International Journal of the Commons

Vol. 4, no I February 2010, pp. 390-403

Publisher: Igitur, Utrecht Publishing \& Archiving Services for IASC

URL:http://www.thecommonsjournal.org

URN:NBN:NL:UI: 10-I-100217

Copyright: content is licensed under a Creative Commons Attribution 3.0 License

ISSN: |875-028|

\title{
Self-governance and international regulation of the global microbial commons: introduction to the special issue on the microbial commons
}

Tom Dedeurwaerdere

Centre for the Philosophy of Law, Université catholique de Louvain, Belgium, Tom.Dedeurwaerdere@uclouvain.be

For millennia people around the world have exchanged biological materials, mainly for food and agricultural purposes (Morgan 1979; Diamond 1997; Brush 1998). Crop domestication began about 12,000 years ago, and moved rapidly across continents and even inter-continentally. Colonialism and imperial trade in the 1500s and 1600s accelerated things rapidly, to the point where people were eating much the same staples all over the world (Braudel 1992). In the last century, however, the emergence of in vitro cell culture technology and molecular biology has led to tremendous increases, both in the quantities of biological resources exchanged and in global interdependencies (Parry 2004). In particular, the global distribution and exchange of microorganisms became an important component of contemporary life sciences. This movement is related to several scientific developments, among which the introduction of improved techniques for the handling and long-term maintenance of living microbiological samples (e.g. freezing, freeze-drying), and thus easier and safer shipping of samples, had a major impact. Similarly, the development of innovative methods for the isolation and cultivation of novel microbial strains, the genomics revolution, and the broader impact of globalization of research in the life sciences in general enhanced interest and cooperation in microbial research.

As a result, vast amounts of plant and animal genetic material are collected and microorganisms isolated throughout the world from various habitats and sources, and exchanged in collaborative research networks for the improvement of global food security, public health and climate change mitigation. For instance, in the 1980s, Africa faced the destruction of a major crop, cassava (also known as manioc), by a scale insect, the mealy bug (Hammond and Neuenschwander 1990). Through research in Latin America on the natural enemies of this bug, a 
predator was identified, imported into Africa and successfully used in a major biological control programme. As a result, millions of dollars of food crops were saved. Other well-known examples of the worldwide sharing of biological resources involve microbial materials. For instance, soy bean production throughout the world has been improved through the use of nitrogen fixing bacteria, the root nodule bacteria. Through the worldwide exchange of some well-characterized and high-performing isolates of these bacteria, they are used in public and private research, for training and education, and commercially produced in large quantities in various countries (CGRFA-11/07/Circ-3). Currently, more than half a million microbial strains (that is microorganisms that are grown on a nutrient medium), which have been collected in various countries, are distributed throughout the world every year by the culture collections that are members of the World Federation of Culture Collections alone, mostly for the marginal costs of distribution (Dedeurwaerdere et al. 2009). Another example, from the field of human biological materials, is the case of Huntington's disease, a major neurodegenerative disease. In the 1980s, research into this disease was greatly enhanced by the collection of human tissue in regions of the world where it is highly prevalent (Conneally 1984). A world-wide collecting effort, and subsequent research, allowed the genetic location responsible for this disease to be identified. The results of this research are now being used in the development of improved diagnostic tools.

Nevertheless, the relatively frictionless exchange of biological materials within a global commons, which prevailed during the early days of modern life sciences, now seems to be reversed. More and more biological materials are enclosed behind national and privatized fences, or only accessible under very restrictive license conditions. For instance, recent research on avian bird flu has been hampered by countries, such as Indonesia refusing to provide access to samples of the H5N1 virus (WHO 2007). In this case, the Indonesian government feared that foreign companies would acquire the rights to any vaccine which might eventually be developed, without proper guarantees of low-cost access to this vaccine for developing nations. After an agreement in 2007 (World Health Assembly 2007) to start negotiations to define the terms of references for fair and equitable sharing in any possible profits, Indonesia resumed sharing the H5N1 avian influenza virus samples.

More generally, the implementation of access and benefit-sharing (ABS) obligations at the national level has led to the adoption of quite restrictive access measures in several developing countries, probably as a reaction to the excesses of bio-prospecting and patenting by developed countries (Safrin 2004). These access procedures can lack transparency and be quite complicated, involving lengthy delays in obtaining genetic materials (UNEP/CBD/WG-ABS/5/3 2007, 12-13). Another case of increasing restrictions on the access and use of microbial materials concerns the distribution of microbial strains by public culture collections. A major breach in the traditional sharing practices is the introduction by some collections of restrictive licenses. Some of these even forbid distribution to other public 
culture collections of basic taxonomic reference materials, such as type strains acquired from another culture collection (Dedeurwaerdere et al. 2009).

One of the major factors that has contributed to these increasing threats to enclose the global commons in biological materials is the emergence of the global intellectual property regime during the 1990s. In the field of plant variety protection, since 1991, successive versions of the agreement of the International Union for the Protection of New Varieties of Plants (UPOV) (signed by all the major OECD countries) have progressively restricted the rights of farmers to reuse their own seeds and to improve upon them in farmer-exchange networks (Brahy 2008, 204-10). At the global level, the 1995 agreement on Trade Related Intellectual Property Rights (TRIPS, 1 January 1995) resulted in an extension of the possibilities of patenting living materials in national jurisdictions (Sampath 2005). In principle, this agreement contained clauses that could have been useful for building a commons. They mainly laid down the option of developing sui generis property rights regimes, including forms of collective property rights. Moreover, parties to the Treaty are free to develop a less protectionist approach, as long as some minimal common rules are complied with (Reichman 2000). However, these possibilities have remained largely unexplored. Indeed, political pressure and lobbying have led to a restrictive interpretation of TRIPS in national jurisdictions (Drahos 2002), which has resulted in the extension of the private property rights regime.

In the field of the governance of biological diversity, the 1993 Convention on Biological Diversity (CBD, 29 December 1993) abandoned the common heritage doctrine that had previously prevailed in some areas of the regulation of biological resources (such as plant genetic resources (Marin 2002)) and instituted national sovereignty over all biological resources. One of the objectives of the Convention was to create an incentive for the conservation of resources by countries who can now claim a fair and equitable share in the profits generated from their use by other countries, through both monetary and non-monetary means. However, the implementation of the Convention led to increasingly complex administrative and regulatory frameworks, which meant that in practice it became very difficult to share the resources (Roa-Rodríguez and van Dooren 2008). Scientists have repeatedly expressed concern about the harm that restrictive access regulations might have on scientific research (Jinnah and Jungcurt 2009, 464).

Public and private bodies have taken various initiatives to preserve the biological materials commons in this increasingly hostile environment (Cook-Deegan and Dedeurwaerdere 2006). In some instances private companies have even taken the led in pushing forwards the commons, as was famously the case in the mid1990s when Merck released its internal database of human gene sequences to the public domain, in order to counteract the movement to privatize the human genome (Williamson 1999). This move was corroborated by other public initiatives, such as the Bermuda declaration in 1996, which proposed mandatory disclosure of all new sequences as a condition for publication or research results in scholarly journals. Subsequently this principle has been adopted by all the major life-science 
journals and all known human genome sequences were disclosed through publicly recognized global databases in the framework of the International Nucleotide Sequence Database Collaboration.

A vast body of research has been developed addressing how the life-science research commons should be governed, in the context of a globalized intellectual property regime (for an overview see, for example, Maskus and Reichman 2005 or Hope 2008). Scholars revised the basic concepts of research on the commons to adapt it to the realm of knowledge and information (Hess and Ostrom 2007). In particular, the collective action problems analyzed in the context of the natural resources were reformulated in a manner more appropriate to the study of the global sharing of biological materials (Hess and Ostrom 2006). The goal of this special issue is to advance this research agenda.

In the context of research on the life-science and information commons, the word "commons" has been defined as a general term to refer to any resource that is shared by a group of people, where those people participate in making decisions about how those resources should be used (Hess and Ostrom 2007, 4). This broad definition is adopted in this special issue. In the various papers, the core reference case is the study of design principles for building the microbial commons; another important example, the global crop commons, is also extensively considered. The microbial commons deals with a set of microscopic biological materials belonging to the eukaryotic and prokaryotic domain of life, the most common of which are bacteria, fungi, yeasts, algae and viruses. What has been referred to as the global crop commons in the article by Halewood deals mainly with the plant genetic resources used in food and agriculture.

The main focus of the papers in this special issue is on the role of governance in building the genetic resource commons. As in other fields concerned with global public goods, various mechanisms of governance, in addition to governmental or intergovernmental rule making, play an important role in addressing the main collective-action problems that have to be solved. Therefore, the interest is, in a very general way, in the contribution of various mechanisms of collective decision making to the working and the building of the genetic-resource commons. Such mechanisms can be based on a variety of premises, including selfgovernance in global science communities, participatory modes of governance in international non-profit organizations, and conventional intergovernmental negotiation forums.

A convenient framework to present some of the main governance issues in such a comparative perspective is the Institutional Analysis and Development (IAD) framework, which has been applied to commons analysis in many other situations (Ostrom 2005). This framework is used here to distinguish between some of the main attributes of the microbial and the global-crop commons. These include the biophysical characteristics of the resource, the attributes of the community and the nature of the institutional rules in use. The precise nature of these attributes and rules is developed in more depth in the papers by Byerlee and Dubin, Halewood, and Fritze in this special issue. In line with the main topics of 
the papers, the focus here is on the attributes of the biomaterials, the attributes of the digital information commons relevant to the analysis of the microbial commons have been explored elsewhere (Hess and Ostrom 2006).

The first attributes that raise specific governance problems in the case of genetic resources are the biophysical characteristics of the resources. Swanson and Goeschl (1999) describe some of the main biophysical characteristics of genetic resources that are related to aspects of the goods that are more efficiently provided through non-market means (such as open-source collaborations and public provision). Genetic resources are complex goods with both a biophysical and an informational component. As biophysical entities, both crop and microbial genetic resources are widely scattered, whether originally in nature or as a result of human domestication. In general it is costly (or simply difficult) to exclude users from accessing these resources, particularly because basically similar individuals of the same species can be found in various places (Dedeurwaerdere et al. 2009). The particular economic value (not considering its ecological economic value) of the biological resources is mainly realized at the end of the innovation chain, where they led to commercial applications and where intellectual property rights (IPR) can be attached; the main value of the raw resources, which serve as the input to the innovation process, is more systemic (Swanson and Goeschl 1999). Examples of this are the role of biological materials in sustaining a healthy ecosystem for its landscape or biodiversity value - the importance of which is often only understood restrospectively, when the ecosystem is not functioning properly any more -, and the possibility of accessing a wide variety of samples within a population to increase scientific understanding. These systemic values often have to be addressed through non-market institutions.

The main reason for the recourse to non-market institutions, however, lies in the informational nature of genetic resources. Genetic resources as informational goods contain sequences that can express potentially useful traits for making progress in health, agriculture, climate change and other issues of global concern. The value of many of these traits will only become manifest through future scientific developments or as a response to new features of the natural environment resulting from changes, such as genetic mutations. Therefore, progress in the life sciences in the future will depend on present-day investment in information goods which are still of uncertain value. Both ex-situ (Dawyndt et al. 2006) and in-situ (Brush 1998; Nicholas 2005) conservation are involved.

The second set of factors that impact on the choice of governance mechanisms is the attributes of the communities. The microbial and the global crop communities studied here have very different community attributes. The communities involved in the global crop commons, in spite of being globally distributed, are quite homogeneous. The plant breeding programmes within important networks, such as the Consultative Group for International Agricultural Research (CGIAR), are all focused on a common strategic goal, which is global food security. There is a deliberate investment in training and exchange programmes within these networks to foster commitment to common values and common understanding. 
This situation differs greatly from that of the microbial commons, where the communities are much more heterogeneous. The various culture collections often serve very different user groups, such as hospitals, biotechnology companies and agricultural research. Moreover, some of them are general purpose collections with in-house research facilities, while others are very specific or have few research activities (Stern 2004). However, most of the collections (over $80 \%$ for those that are a member of the World Federation of Culture Collections) are publicly funded, with a strong commitment to the public availability of biomaterials. There is a long tradition of international cooperation amongst culture collections in various regional networks (Dedeurwaerdere et al. 2009).

Finally, the important differences between the microbial and the global crop fields in the rules used to organize the commons also deserve to be mentioned. Byerlee and Dubin's article characterizes the "open source collaboration" within the global crop commons built up in the CGIAR network by five rules: (i) free distribution and redistribution of the original materials; (ii) free redistribution of materials derived from the originals; (iii) full sharing of information; (iv) nondiscrimination in participation in the networks; and (v) intellectual property rights on final materials that do not prevent their future use in research.

Except for some nuances, these rules also define exchange practices in the microbial commons. The main difference between the global crop and the microbial commons concerns the rules governing participation in the networks and the mechanisms that trigger benefit-sharing with the original depositors. As discussed in detail in the paper by Fritze, access to the microbial commons is restricted to qualified participants who can handle the microbial materials under appropriate management and laboratory conditions and which have the required legal permits. This rule is necessary because of the particular nature of the resource, to guarantee the continued purity and viability of copies of the original material, and to prevent harm to people or the environment. It is reflected in the fact that most collections participating in the commons only permit qualified participants (such as other culture collections) to redistribute the materials they receive.

The International Treaty on Plant Genetic Resources for Food and Agriculture (the FAO Treaty) specifies the rules that govern benefit sharing within the global crop commons. Benefit sharing is triggered (in part) by the incorporation into new commercial products of germplasm (that is the seeds or parts of the plants that allow reproduction) from the pool of plant genetic resources that fall under the International Treaty. Benefit sharing in the microbial commons is regulated by default through the Convention on Biological Diversity (except in countries that have not signed). Implementation is still carried out on a case-by-case basis, and it remains to be seen if countries of origin will systematically claim rights to benefit sharing when commercial use is made of biomaterials they have deposited. Survey data from nine major culture collections which use formal deposit forms shows that nearly all new materials are deposited without such conditions (Dedeurwaerdere et al. 2009, 27). 
On the basis of this brief presentation of the attributes of the genetic resource commons it is clear that there is a wide variety of action situations, which require a variety of institutional solutions and means of governance. The various papers in this special issue present some of the most innovative institutional solutions in this field, and discuss the contribution of some of the main governance mechanisms to the building of the genetic resource commons. The papers explore the contributions of intergovernmental arrangements (Halewood, Gotor and Caracciolo), international organizations and participatory governance (Byerlee and Dubin), and self-governance (Harvey, McMeekin and Fritze).

The paper by Michael Halewood focuses on the contribution of formal intergovernmental arrangements to building and sustaining the genetic resource commons. Intergovernmental arrangements have an important role to play as a possible solution to overcoming the classic free-rider problem, if a sufficient number of players are willing to invest resources in the operation of such an arrangement. The free-rider problem also threatens the sustainability of the genetic resources commons. Materials within the commons are usually collected under the assumption that they will remain available for further distribution, thereby creating the network effects (each party having access to more resources than they contribute) and knowledge spillovers (promoting growth in various other sectors) which are the main collective benefits of the system. However, any party can decide at any moment to opt out of the system (and to seek private rents by doing so), either by introducing restrictions on the use of materials held in a collection within their national boundaries, or by imposing restrictions on the use on materials originally collected in their country, but held in a collection in another country.

The papers by Halewood and by Gotor and Caracciolo clearly show the impact of this threat of free riding for the long-term sustainability of the commons, in the particular case of the global crop commons established by the CGIAR. In the immediate aftermath of the adoption of the Convention on Biological Diversity in 1993, uncertainties about the legal status of ex situ collections of plant genetic resources for food and agriculture were heightened. It was feared that host countries would claim control over the CGIAR centres or, alternatively, that the international collections of the CGIAR network would be placed under the direct bureaucratic control of the World Bank. Similar concerns have been raised in the context of the microbial commons, as some culture collections threaten to opt out of the collaborative sharing regime by applying restrictive license conditions for the distribution of materials. These moves have been strongly criticized by the community, as many of the materials held in national collections were originally sourced in other countries, both before and after 1993, on the assumption that they would be made fully available to the broad scientific community.

The argument put forward in the papers by Halewood and by Gotor and Caracciolo shows how intergovernmental negotiation can contribute to alleviating some of these collective action problems. Intergovernmental action can take various forms, such as the drafting of a fully fledged international treaty or contractual 
agreements between an international organization and individual members of a "coalition of the willing", such as the In Trust Agreements of 1994 between FAO and the individual CGIAR centres. This agreement, in which the ex situ collections of plant genetic resources hosted by the CGIAR centres were placed under the authority of the FAO Commission on Genetic Resources (CGRFA) seems an especially interesting solution, in the absence of an international treaty. The CGR was placed in charge of negotiating and supervising the In Trust agreement between the CGIAR centres, and provided coordination and monitoring as a trusted intermediary and external party to the CGIAR centres. In the same time, the actions of the CGR were backed up by the national governments approval of the work of the CGR through the FAO. Halewood in particular makes the case that for the microbial commons the only way to prevent a race to the bottom (in which more and more collections would opt out of the commons) between the national $e x$-situ collections is to rely on intergovernmental negotiation forums, such as the CGR commission, in coordination with other UN-related bodies dealing with climate change and public health.

The focus of the paper by Byerlee and Dubin is the role of international organizations in the building of the global crop commons, and the more recent moves in international organizations away from centralized bureaucratic decision-making and towards participatory breeding and decentralized decisionmaking. The role of organizational learning in the establishment of common norms and understandings in the early days of the institutionalization of the global crops commons cannot be underestimated. As also recognized by Halewood, the complexity of global economies is so great that centralized and formal law creation cannot effectively cope with the need to achieve normative regulation among communities of individuals who repeatedly face collectiveaction problems. Even recent work on the implementation of a formal global legal regime for the crop commons within the FAO Treaty continues to rely on concrete experience with open-source collaboration in the breeding and training programmes distributed over the world and coordinated through the various centres of the CGIAR network.

The paper by Byerlee and Dubin deals with the history of open-source collaboration, which was at the basis of the green revolution in the late 1960s1970s. It shows the importance of strong bonds amongst scientists, and common goals amongst the various organizations and individuals involved. Field training of young scientists in the nurseries of the network, and workshops amongst senior scientists played an important role in this. However, the key element seems to have been the preservation of a sense of involvement in the decisions over the breeding process by the participants. Indeed, germplasm produced within the CGIAR network is distributed as an international public good, while the development of plant varieties based on the germplasm and distribution to farmers is organized by the participating countries and organizations. Further innovation in the working of the CGIAR further accentuates the importance of participation in decision making. Extensive consultation with and even involvement of farmers 
in breeding is increasingly accompanying the search for valuable new traits, especially in the cases of remote areas and the needs of farmers with few means of subsistence.

The third set of papers, by Harvey and McMeekin and by Fritze, zooms in on the contribution of self-governance to the working of the genetic resources commons. The focus in these papers is on the need to go beyond the dissociation between users and producers of knowledge within the commons. Indeed, as Harvey and McMeekin remind us, knowledge is not depleted by use, but actually grows and develops with use, especially when combined with collective examination and testing. Moreover, once it is constructed as a public certified and testable knowledge brick, the result of knowledge production is not only an end product, but an input to new knowledge generation processes. This is shown most dramatically in the case of online bio-databases, such as the international public genome databases. In this case, the discovery of new functional properties of gene sequences can be achieved through similarity searching involving the entire space of available sequences on public databases. The results of such discoveries, when they led to the identification of interesting new gene tags, are in turn deposited in the public databases, thereby adding to the total search space available for future similarity searches.

The need to involve the user communities in the management and production of the upstream knowledge assets has led to a set of interesting institutional innovations which are discussed in these papers. These include the public genome databases, open source bioinformatics software, and viral licensing by culture collections through so-called legitimate exchange. The key point to be made here is that these institutional innovations were not established through governmental or intergovernmental legal or policy arrangements. They were the result of self-governance by the science and microbial culture-collection communities. For instance, as Harvey and McMeekin show, bioinformatics software defines the way the similarity of gene sequences is constructed (in particular by defining the margins of error in a certain way), and, therefore, directly impacts on our understanding of biological processes. Scientists reverseengineered some of this software or rebuilt it from scratch in order to release it under open-source rules. This move was needed to allow continuous and collective verification of the way knowledge of genetic sequences is constructed in the digital information space.

A similar concern with the problem of collective control over the validity and authenticity of basic science inputs has led to open-source-inspired institutional solutions in the microbial commons. The case of the European Culture Collections' agreement on standard contractual clauses discussed by Dagmar Fritze is the first worldwide formalization of community-driven rules for the exchange of biomaterials based on open-source principles. Under these rules, a culture collection can further distribute biomaterials within the commons, as long as it uses equivalent and compatible contractual provisions as those in place at the supplying collection. The agreement is intended to build this global semi-commons, while 
preserving the main characteristics that define the microbial resources held at the culture collections which serve as publicly certified and authenticated knowledge bricks available for further follow-on research and uses.

What are the main lessons that can be learned from these papers for the governance of the genetic resource commons? First, due to the dual nature of genetic resources (as a biophysical resource used in current applications and as a living and evolving informational resource which provides basic input for the development of future applications and uses) the line between the market and non-market value of genetic resources is very difficult to draw. This point is made explicit in the paper by Harvey and McMeekin, which traces the continuous experimentation with hybrids by market and non-market institutions within the institutional development of the digital information commons. However, it is also a common theme present in other papers. As a consequence, the design of institutional rules and governance mechanisms for the commons will have to take into account this profound polyvalence in use, even though its core will be oriented to non-market values, such as contributions to fundamental research and the conservation of landscape and ecological values.

Second, the papers in this special issue clearly establish the diversity of governance mechanisms in this field. The main witness to this is the fact that the governance solutions in place today in the global crop and the microbial commons are very different, in spite of the fact that they use very similar institutional design principles to organize open-access collaborations (see the contributions by Byerlee and Dubin, and by Fritze). Some of these differences in governance choices can be related to the different history of the two fields and to major differences in the community attributes. However, as Halewood emphasizes, the greater weight being attached to self-governance through science communities and collection managers in the microbial commons leaves some important problems unsettled in the global microbial commons, such as the global equity problems that are addressed in the context of the ongoing negotiations on Access and Benefit Sharing. In the absence of proactive involvement of these communities in these negotiations pertaining to global equity, there is a risk that the outcome might undermine the commons based governance of microbial resources.

Thirdly, due to the relationship between the different domains of the genetic resource commons, it is clear that a mutually supportive relationship between various governance activities is an important feature of a successful genetic resource commons. This can be thought of as an organization with multiple layers of nested enterprises, which has been recognized as an important characteristic of large-scale and robust common pool resource systems (Ostrom 2005, 269). For instance, as stated above, the success of the intergovernmental negotiation processes that led to the FAO Treaty, was in large part due to the knowledge and expertise built up in the context of the CGIAR network, and international agricultural research generally, about a commons that was already operating well. The collective learning in agricultural research (coupled with the highly politicized nature of genetic resources issues in the 1980s and 1990s) paved the way for 
the formal legal arrangement in the context of the FAO. The strong normative community built around the CGIAR network continues to play an important role in the development of and experimentation with solutions that show the way forward in the implementation of the Treaty.

The interdependence between various governance activities is also a key feature of the microbial commons. The self-governing arrangement within the European Culture Collection Organization, which was discussed above, is based on private rule making by the collections under the constraints of international regulation of biosecurity and access- and benefit-sharing. In current circumstances, this arrangement is based on the participants' strong normative commitment to quality management and tracking the flow of resources, and relies on trust built through extensive face-to-face contact between scientists and culture-collection managers. However, this arrangement could come under pressure if future ABS negotiations impose high costs on simple transactions involving basic scientific inputs. On the other hand, a mutually supportive relationship between the selfgoverning arrangement and the legal framework in the context of ABS would certainly be beneficial to both. The tracking system in place in the microbial commons can increase transparency and provide useful information for the operation of the international regime. Similarly, the recognition under CBD (under certain conditions) of tailor-made and workable ABS systems designed by communities of practitioners, such as those adopted in the European Culture Collection Organization (ECCO), would certainly be a major incentive for more players to formalize their informal exchange practices.

Such a system for the microbial commons has been the subject of recent efforts in academic scholarship and high-level policy debate, notably an international workshop attended by the main authors of this special issue (12-13 June 2008, see http://www.microbialcommons.ugent.be/) and an interdisciplinary monograph which envisions various institutional means of further formalizing the informal system that currently prevails in many parts of the microbial commons (Reichman et al. in preparation). Efforts to formalize the informal system could be solely based on self-governance by the participants, or could eventually benefit from the legal assistance of an international organization, such as the Commission on Genetic Resources for Food and Agriculture. The common goal is to avoid the disadvantages of both an international legal arrangement that is too broad to take into account the specificities of transactions involving microbial genetic resources, and of an informal system of transactions based on tailor-made case-by-case conditions which do not provide sufficient legal certainty to the participants.

The prospects of mutually supportive developments between formal international legal frameworks, the programmes of international non-profit organizations, and self-governance arrangements in the scientific and collection communities are at the core of the contributions to this special issue. As will be seen, the interdependency and mutual support between these activities has been at the heart of developments in the field of the global crop commons, and is receiving increasing attention in current initiatives within the microbial commons. 
In particular, the MOSAICC (Micro-organisms Sustainable Use and Access Regulation International Code of Conduct) guidelines assume that, although its members operate in different legal systems, designing a model contract for members of the World Federation of Culture Collections (WFCC) would facilitate exchanges (BCCM 2000). It even suggests that there is a need to establish common rules for access to microbial genetic resources, complementary to national regulations on ABS and existing IPR laws that would govern a demarcated space for the "microbial commons". These and other initiatives have sometimes been frustrated by uncertainties within countries about their own standards and processes for regulating access (Smith 2003), which may best be addressed at an international level through some form of agreement. However, to the extent that such a standard material transfer agreement would harmonize the servicing of culture collections across the globe, it would lay the basis for a de facto commons for the global conduct of microbial research in the foreseeable future.

\section{References}

BCCM. 2000. Elaboration and diffusion of a code of conduct for the access to and sustainable use of microbial resources within the framework of the Convention on Biological Diversity. BCCM, http://bccm.belspo.be/projects/mosaicc/docs/ code.pdf

Brahy, N. 2008. The Property Regime of Biodiversity and Traditional Knowledge. Brussels: Larcier.

Braudel, F. 1992 (first published in 1979). Civilization and Capitalism, 15th18th Century, Vol. I: The Structure of Everyday Life. Berkeley: University of California Press.

Brush, S. B. 1998. Bio-cooperation and the benefits of crop genetic resources: the case of Mexican Maize. World Development 26(5):755-766.

CGRFA-11/07/Circ.3, Technical issues relating to agricultural microbial genetic resources (AMIGRs), including their characteristics, utilization, preservation and distribution: A draft information paper prepared for the Genetic Resources Policy Committee (GRPC) of the CGIAR, (based on the information document prepared by J.G. Howieson).

Conneally, P. M. 1984. Huntington disease: genetics and epidemiology. American Journal of Human Genetics 36(3):506-526.

Cook-Deegan, R., and T. Dedeurwaerdere. 2006. The science commons in life science research: structure, function and value of access to genetic diversity. The International Social Science Journal 58(2):299-318.

Dawyndt, P., T. Dedeurwaerdere, and J. Swings. 2006. Exploring and exploiting microbiological commons: contributions of bioinformatics and intellectual property rights in sharing biological information. Introduction to the special issue on the microbiological commons. International Social Science Journal 188:249-258.

Dedeurwaerdere, T., M. Iglesias, S. Weiland, and M. Halewood. 2009. Use and exchange of microbial genetic resources relevant for food and agriculture. 
Report submitted to the Twelfth Regular Session of the Commission on Genetic Resources for Food and Agriculture, 19-23 October 2009, forthcoming.

Diamond, J. 1997. Guns, Germs, and Steel: The Fates of Human Societies. New York: W. W. Norton.

Drahos, P. 2002. Negotiating intellectual property: between coercion and dialogue. In Global Intellectual Property Rights: Knowledge, Access and Development, ed. P. Drahos, 161-182. New York: Palgrave Macmillan.

Hammond, W. N. O., and P. Neuenschwander. 1990. Sustained biological control of the cassava mealybug Phenacoccus manihoti [Hom.: Pseudococcidae] by Epidinocarsis lopezi [Hym.: Encyrtidae] in Nigeria. BioControl 35(4):515526.

Hess, C., and E. Ostrom. 2006. A framework for analyzing the microbiological commons. International Social Science Journal 58(2):335-350.

Hess, C., and E. Ostrom. 2007. Understanding Knowledge as a Commons: From Theory to Practice. Cambridge, MA: MIT Press.

Hope, J. 2008. Biobazaar: The Open Source Revolution and Biotechnology. Cambridge, MA: Harvard University Press.

Jinnah, S., and S. Jungcurt. 2009. Global biological resources: could access requirements stifle your research? Science 23(5913):464-465.

Marin, P. L. C. 2002. Providing Protection for Plant Genetic Resources. New York: Kluwer Law International.

Maskus, K. E., and J. H. Reichman, eds. 2005. International Public Goods and Transfer of Technology: Under a Globalized Intellectual Property Regime. Cambridge, UK: Cambridge University Press.

Morgan, D. 1979. Merchants of Grain. New York: Penguin Books.

Nicholas, F. W. 2005. Animal breeding and disease. Philosophical Transactions of the Royal Society of London, B Biological Sciences 360(1459): $1529-1536$.

Ostrom, E. 2005. Understanding Institutional Diversity. Princeton: Princeton University Press.

Parry, B. 2004. Trading the Genome. New York: Columbia University Press.

Reichman, J. 2000. The TRIPS Agreement comes of age: conflict or cooperation with the developing countries? Case Western Reserve Journal of International Law 32:441-470.

Reichman, J. H., T. Dedeurwaerdere, and P. F. Uhlir. in preparation. Designing the Microbial Research Commons: Strategies for Accessing, Managing and Using Essential Public Knowledge Assets.

Roa-Rodríguez, C., and T. van Dooren. 2008. Shifting common spaces of plant genetic resources in the international regulation of property. The Journal of World Intellectual Property 11(3):176-202.

Safrin, S. 2004. Hyperownership in a time of biotechnological promise: the international conflict to control the building blocks of life. American Journal of International Law 98:641-685.

Sampath, P. G. 2005. Regulating Bioprospecting: Institutions for Drug Research, Access, and Benefit-sharing. Tokyo: United Nations Press. 
Smith, D. 2003. Culture collections over the world. International Microbiology 6:95-100.

Stern, S. 2004. Biological Resource Centres: Knowledge Hubs for the Life Sciences. Washington, DC: The Brookings Institution.

Swanson, T., and T. Goeschl. 1999. The management of genetic resources for agriculture: ecology and information, externalities and policies. In Food Security, Diversification and Resource Management: Refocusing the Role of Agriculture, eds. G.H. Peters, and J. von Brown. Brookfield: Ashgate.

UNEP/CBD/WG-ABS/5/3. 2007. Analysis of gaps in existing national, regional and international legal and other instruments relating to access and benefitsharing.

World Health Assembly. 2007. Pandemic influenza preparedness: sharing of influenza viruses and access to vaccines and other benefits, WHA60.28, 23 May 2007.

WHO. 2007. Indonesia to resume sharing H5N1 avian influenza virus samples following a WHO meeting in Jakarta. News Release, 27 March 2007. Available on http://www.who.int/ mediacentre/news/releases/2007/pr09/en/index.html

Williamson, A. R. 1999. The Merck gene index project. Drug Discovery Today $4: 115-122$. 